\title{
EFFECTS OF DIGITAL PRINTING APPLICATIONS ON CONTEMPORARY ART
}

\author{
Yeter Beris \\ Altinbas University Vocational School, Graphic Design Department, Istanbul, Turkey
}

\begin{abstract}
Today's technology and innovations, which have a power in representing society's cultural values and emotions, offer new possibilities to the most important expression tools of social life. In fact, it is stated that with this power of representation, it shapes the cultures and societies as well. In this representation, art is stated to play an important role in shaping the expression of social emotions and life by being embedded in them and taking the support of technology (Schiuma, 2011). As a necessity for the age, humans now communicate through art, strengthening the individual expression in social life with advantages offered by technological production and incorporate new expression tools into their lives.

Continuing to explore the conveniences offered by technological life, humans continue their development in their social life through communication and interaction in the virtual world. Thanks to this interaction, digital communication channels have spread rapidly and the desire to access information easily has also created the technological infrastructure requirements that are able to provide, economical, high quality and personalized designs for demands changing consumer habits as requirement of this era, decreasing printing circulation due to this, and personalized designs taking center stage have accelerated the spread of digital inkjet printers with toner cartridges. Digital printing systems that have emerged since the year 2000 offer a new laboratory environment that today's artists can experience as a means of expression, beside their technological developments. Fine-Art print, with a view that acknowledges the importance of digital art in the technological life of our era, is a new expression tool worth mentioning its role and importance in contemporary art. Fine art print, as a term, defines the prints made by high-quality inkjet systems of images transmitted from digital files to the special production underprint materials under the supervision of the artist himself/herself.

In this research, fine art print technique which presents the artistic expression to the viewer with today's technology will be discussed. It is aimed to examine the values it adds to contemporary art and technological advantages as a production material that supports artistic expression and its effects on artists' material preferences.
\end{abstract}

Key words: fine art print, digital print, contemporary art

\section{INTRODUCTION}

After the industrial revolution, technological and scientific developments have facilitated human life, and the speed of life and technology have improved the way people communicate and learn. Due to this, the world wars which caused social and cultural destruction as well as the participation of technology in the life since the early 1900s, have also contributed to the transformation of the means of expression and the production techniques. After II. World War, the invention of the computer brought this change to an irreversible point. This great invention, which was the beginning of the modern era, has been the harbinger of the periods when technology has guided communication, the developments could not be kept up with and the art would meet technology.

The technological facilities offered by the computer in every field of life have been rapidly adopted by the people and have created more demands and the communication methods developed with urbanization have gained a strong momentum with the possibilities of the computer. Thanks to the digital communication, people can communicate in seconds by pressing a button and transfer information to many points of the world. Now in the age of such a speed, the development of faster communication methods in the business world has been inevitable. "The rapid dissemination of digital communication channels and the desire to easily access the information has also created the technological infrastructure where the demands are made to provide economic, and personalized designs of high quality" (Beris, 2015). It is also possible to see these developments in the printing sector, which has been commercially available since the 16th century. The printed media, which has been produced after days of preparation with traditional methods, are replaced by the personal design and communication channels that can be printed on all kinds of surfaces in digital tracks just in a few minutes. This change has been reflected in the computer and programming languages that have been developing since 1950 and has been seen in the artistic expressions of contemporary artists such as Andy Warhol. The reflections of this 
interaction continued to develop at the same rate in 40 years. Today's art experiences individual expression and communication with the advantages offered by technological production and incorporates new means of expression. In other words, it has become one of the most important means of expression of cultural and social life with the power of representation in the expression of the cultural values and emotions of society. It is stated that this representation power shapes cultures and societies. In this representation, art plays an important role in the expression of social emotions and shaping life (Schiuma, 2011). Human beings are now communicating through art, empowering individual expression in social life with the advantages offered by technological production and include new means of expression. Referring to this change in the 1930s, W. Benjamin mentions "The artwork is not independent of the conditions in which it was born" and tells something about today. Fine art print refers to digital prints that are produced by controlling the high-resolution images that are transferred from digital files or digital media by the artist himself/herself and which belong to the artist. In other words, it defines the artistic special print made on the sub-printing materials also called specially produced media with the high-quality inkjet system of high quality.

In this age, which is thought together with the technological life, fine art print, which accepts the importance of digital art, appears as a new phenomenon worth mentioning its role and importance in contemporary art. Before discussing fine art print, which will be the material that will produce the original expression in contemporary art with a new language, it would be useful to take a brief look at the historical development of the art of print.

\section{METHODS}

In this paper, qualitative researches based on records and documents have been used in the field research. It has been referred to the scanning methods of resources recorded on the internet or resources such as professional books and periodicals and this study has been formed within the context of collection of the data of the impression and research based on the work experience from the past years.

\section{HISTORY OF THE PRINTMAKING ART}

Throughout the history, the artist presented his/her thoughts to the viewer starting from the walls of the cave and working on different materials such as paper-canvas, ink, oil paint, watercolor, acrylic, brush, pencil or other tools. The usage preferences of these materials have also varied according to the image imagined by the artist, the final satisfactory result and the visual presentation. It is not known that the artists at that time searched for the new materials since the artistic materials had negative effects on the permanence of the works for many years; however, the developing chemical techniques have found somehow a place in the art movements. This interest also created an environment that made you experience artistic production via original printed picture for the artists of the period who are looking for new expression and expression. The first engravings of the world-renowned German painter Albert Dürer, which are known to have been produced at the end of the 15th century, can be given as an example (Figure 1).

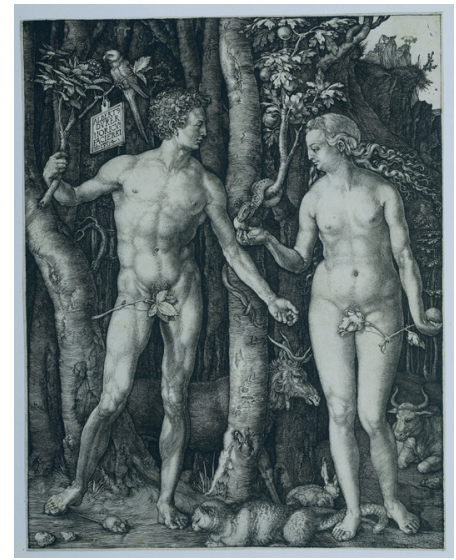

Figure 1: Adam and Eve, Albrecht Dürer, 1504, Engraving, Rijks Museum, Netherland Source: https://www.rijksmuseum.nl/en/rijksstudio/artists/albrecht-durer/objects\#/RP-P-OB-1155,0 
The social-cultural developments of the urbanized communities, the technological and political structures caused the industrial revolution, which is defined as "the breaking point" in the social transformation and the reflection of these developments and searches has been included in the art movements. The inclusion of mass production lines, which are the extension of industrial production, has brought a cultural movement. The urban man who worked in the factory environment had created a separate world for him both to enjoy and rest at night parties. The artists of that period also found a new way of expression in this movement and printmaking art, which can be defined as a mass production band method in the art, created a perception of art in a new language. Posters of entertainment announcements such as cabarets and theaters in the entertainment world, which influenced the city culture of that period, attracted great attention. Printmaking art has become popular with intense interest thanks to these posters produced by mass production techniques such as lithography, wood printing, and engraving. These posters were highly appreciated by the low-income people who could not reach the works of art, and each of the painters who designed the posters created a new school of design that influenced the history of graphic art in Europe (Figure 2).

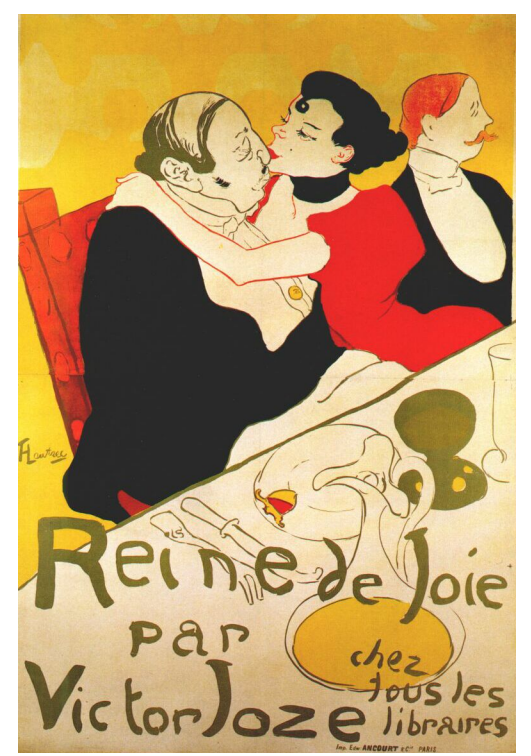

Figure 2: "Reine de Joie" Poster, Lithography, Henri de Toulouse-Lautrec, (French, 1864-1901) Source: http: //www.artnet.com/artists/henri-de-toulouse-lautrec/art-nouveau-ms5QsHaTLycCLjGbdjv-aw2

The fact that production is affordable in every layer in the society and that artworks take place on the streets thanks to cheap production as posters have changed the value perception of the artwork. In this way, the original print art has survived to the present day and has been accepted in the art market. Printmaking Art, created by traditional methods in Europe, has become valuable in the art market as a result of the centuries of radical changes and cultural life. This cultural life has led to the establishment of modern art museums and engravings museums around the world, which recognize the value of the art of printmaking. At the same time, international print biennials and printmaking Competitions also offer activities supporting this interest (Tekcan, 2017).

In the last four decades, the intersection of digital technology with the art world has been thanks to the practices experienced by photographers and artists. Firstly, the photographer or artist applied digital imaging methods to develop his/her own art. These methods have produced demands, thanks to intensive research by scientists, the image quality of inkjet digital prints and ink and sub-printing materials have been developed. In other words, fine art print, among contemporary artists, has been used in the production of a limited number of reproductions or original works of art, since inks are more resistant to light fading with a wider range of colors. For this reason, it is now possible to see fine art print artworks exhibited in contemporary art museums.

The fine art print is based on digital inkjet technology. It is obtained by printing the digital artwork prepared in the digital environment by the artist himself/herself and by printing with a high-quality inkjet digital printing, by numbering in a limited number and by the artist's signature process. Thanks to the latest technological inventions and non-fading inks that incorporate intelligent systems, serial production can now be performed in order to meet the demands of digital production. In addition, high-resolution 
fine art print practices can be done in a short time on a wide range of sub-printing materials using many materials such as canvas, handmade special papers, and watercolors. Although not yet produced at affordable prices, high-quality digital prints can be made with high costs and these satisfy artists. The fact that all kinds of machinery and material supplies of digital printing technology are imported from major countries is also a negative factor that makes it difficult for artists to prefer in terms of cost.

It would not be wrong to say that the foundation of fine-art print is based on the computer and programming language has developed since 1950. Frieder Nake, who started working on computer graphics and art in 1963, is an engineer who is known as one of the pioneers of computer art. When he studied mathematics in Stuttgart, Germany, he and Frieder Nake, A. Michael Noll and Georg Nees performed artistic experiments for the first time in the digital environment. These works were later published in 1965 at the Stuttgart University of Technology with the plotter called "Graphomat Z64", the legendary drawing machine of Konrad Zuse (Nake, 2012). These digital art examples drawn by algorithms that are stated to be entered by interpreting mathematically on ER 56, a room-sized computer, were exhibited in Stuttgart, Galerie Wendelin Niedlich in 1965 and this information can be found in Wikipedia (Figure 3).

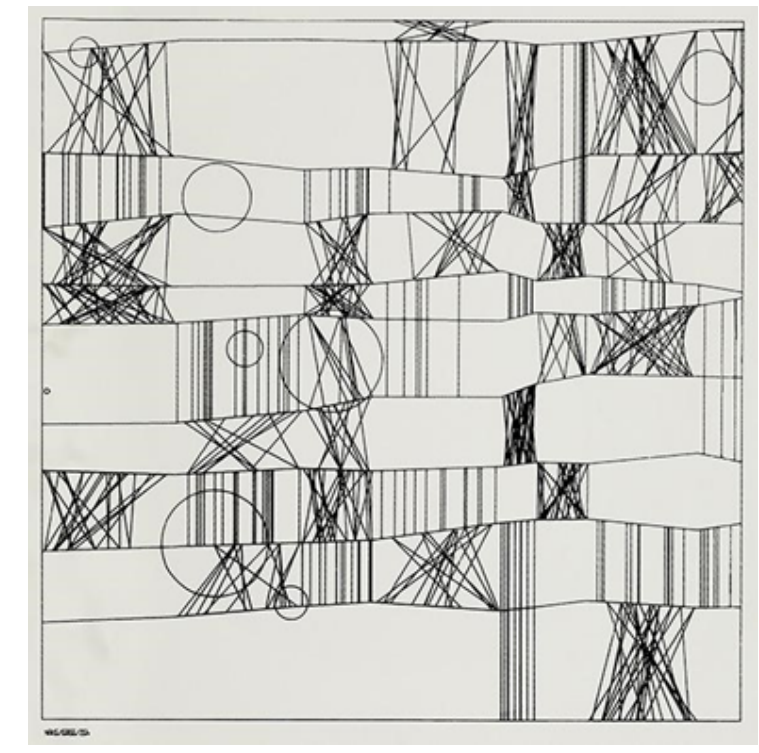

Figure 3: 1965, Frieder Nake tarafindan Paul Klee’ye övgü (Frieder Nake Hommage à Paul Klee), Source: https://iq.intel.com/a-brief-history-of-digital-art

From the 1960s on, new examples of digital art practices were introduced, a photo was scanned by engineers from Leon Harmon and Ken Knowlton, and the grayscale values were converted to various ASCII codes on the IBM 7040 computer and the image was re-created. The work "Nude" was found on the cover of the New York Times magazine, which was presented at a meeting although it was not seen as very successful for that period (Figure 4).

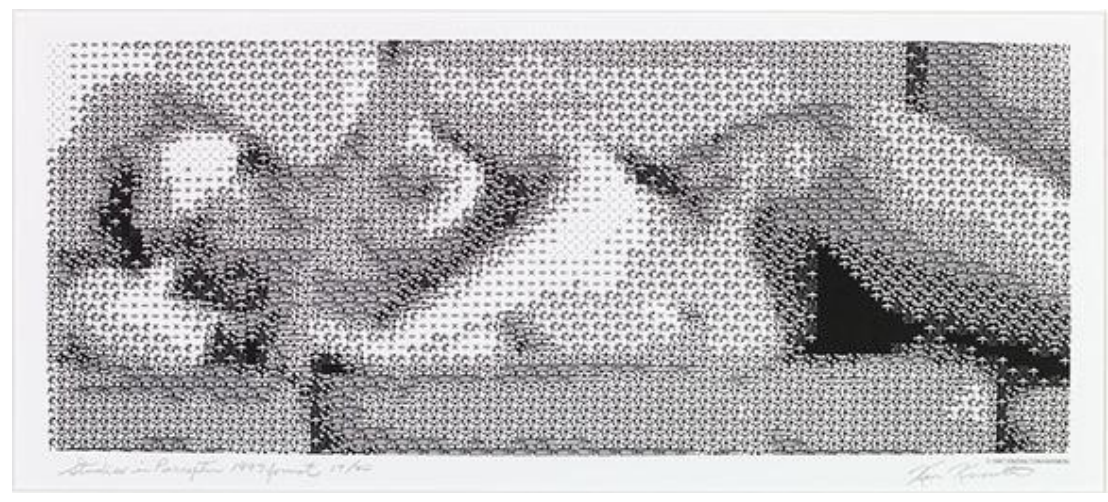

Figure 4: Nude, Bell Labs, 1967

Source: https://iq.intel.com/a-brief-history-of-digital-art 
In the early 1980s, globally-powered computer companies, such as the IBM PC and Apple Macintosh, underpinned the artistic applications of digital media thanks to their breakthrough technological innovations in personal use. These discoveries have heralded the fact that there will be no life like before and incorporated technological systems that facilitate everyday life into our lives. In this period when the computer evolved from binary code to the graphics interface, the efforts of making the individual use of the computer at every moment of the social life provided the rise of computer games. Using the Commoder Amiga computer, one of the popular plays of that period, the American painter Andy Warhol, the most important representatives of the Pop Art movement, got a chance to experience digital art for the first time (Figure 5). The story of the first examples Andy Warhol experienced the digital art in the Commodore Amiga computers in 1985 that they were saved from the old archives almost 30 years after was announced by Andy Warhol Museum (Ford, 2014).

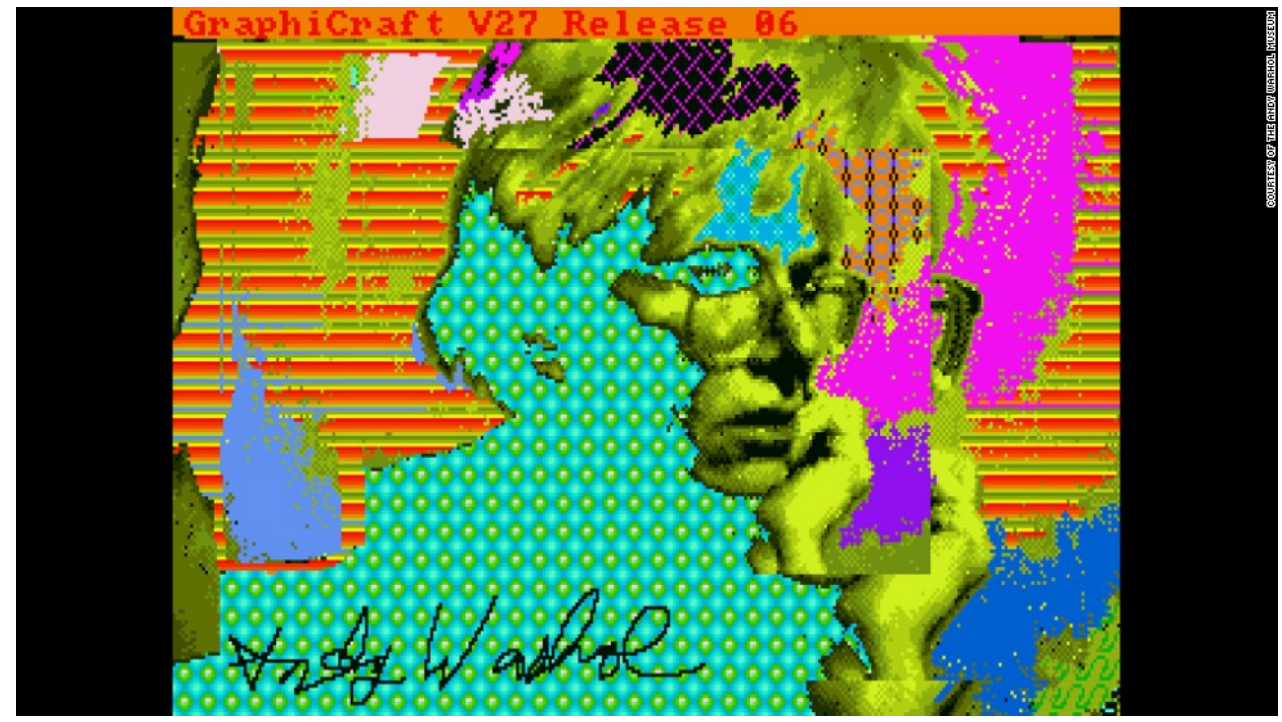

Figure 5: "Andy 2 "Image recovered from Andy Warhol's computer, 2014 Source: http://edition.cnn.com/2014/04/24/us/andy-warhol-lost-art/index.html

The opportunities promised by modern technology to today's art are the reflections of inventions of more than 100 years in which new tools have been presented to artists since 1800s. In the last 30 years, high-resolution digital printing systems, which have evolved from the days of the use of plotter and laser printers, have contributed to the increase in the interest and popularity of fine art Print with its technological ink structure which incorporates intelligent systems. The technological structure, which is now able to present the work prepared in the digital environment, with the desired dimensions and almost the desired sub-printing material, with a fine ink flow of millions of drops per second, has turned into an important opportunity. Accordingly, the development of specially produced sub-printing materials continues to inspire contemporary artists.

In the last 20 years, unlike the limited production of ink-jet color printers, which are used in business and offices, today's new system inkjet printers have improved the image quality of digital art print in incredible ways. Production in this machine track with production capacity in the desired scale can now be seen everywhere. In the light of 100 years of progress, artists have also embraced a new vision and understanding by exploring the use of photography. The new vision of chemists and some artists who use new dyes and pigments to improve science use technology to capture fresh and even ground-breaking interpretations of the rapidly changing world in which they live (Berger, 2005). Digital art prints, which have a large size placement in museums, exhibitions, and architectural buildings, are appreciated as a work of contemporary art by collectors in today's art market. As such, however, the extent to which digital technology will provide radical changes in artistic vision is not yet clear. 


\subsection{The Current Fine Art Print Practices}

First of all, inkjet digital artworks have been defined as "Giclee" print by the printing engineer Jack Duganne. It was stated that these first artistic prints were produced in Iris printers in the early 1990s and that the original works began to fade or deteriorate after a certain period of time. Afterward, it has been stated that the life of the ink and sub-printing materials have been significantly increased by developing technologies and these problems have been eliminated (Nickelson, 2017).

In today's studio environments, using Adobe programs, artworks prepared electronically, with the advantages and facilities offers new opportunities for artists. As such, it stands out as an advantage for the artists who want to produce their work collectively. When an artwork is archived in a digital environment, it is possible to print the desired number of prints with minimum effort and cost. With the professional color separation process, which is controlled by the artist personally, the edition print of the work can be realized in a short time in determined numbers on order or demand without the need for a cost in mass production. The characteristic of edition printing defines the number of prints that can be done at the specified size. The work, which has been approved by the artist with the final print, means that there will be only 50 editions if 50 artistic prints are planned. These editions are called original prints and are printed and signed by the artist in person. In addition, in determining the number of editions, except for the total number of editions under the name of artist copies approved by the artist, there are artistic copies which the artist have and are decided according to the mixed edition and a total number of editions. Thus, by limiting the sale of the work to a certain number, whether it is a photo print or a picture, it turns into a situation where the material value of the work is shared among 50 buyers, which preserves the originality and increases its market value. It means that the artwork can reach low-income art-lovers at an affordable price. Thus, the artist can also share his/her work with more than one buyer through the editions. This sharing process makes contemporary artist prefer this way and this view becomes common.

The fine art print studios of the contemporary museums serving for the artists such as IMOGA in istanbul and the high-quality print with the inkjet printing tracks in the range of millions of colours increase the interest. As such, the inkjet printing system has now a sensitive fine spraying technology like laser printing system. In addition to this advantage, it offers a possibility to print on many sub-printing materials, not only paper, and in almost every size. This creates an opportunity for the artist to adapt the visual she/he wants or needs as a new way of expression.

It is obvious that understanding the stages of this digital printing, the new way of expression takes time for artists and the language of digital software has a complex organization. For the artist, original pre-printing preparation for the designed work is a complex process which the artist can work with the help of another expert. This information environment which covers the digital printing technology that is produced by controlling outside, changing fast and sometimes seems complex is a challenging area which the artist does not dominate yet. This challenging informative and searching process covers the quality of artistic printing in the last three decades and accordingly deterioration, the variety of material, the technologic innovation increasing the option and digital printing processes developing over time. Assessing the longevity of artistic pressure characterized by a variety of ink and media combinations, resistant to fading of artistic prints, is an important consideration as well as being compelling by the artist. These factors include the stability of the printing to environmental conditions (lighting, moisture, and atmospheric pollutants) as well as post-printing options (such as polished printing and canvas prints and montage). Sometimes, as a result of the environmental conditions and after long years, it is possible to see fading of the artworks exhibited in the walls. This is a condition which is not appreciated by the artist. While the artist is able to use the artistic materials she/he uses with the traditional methods with a certain experience, she/he has little experience and knowledge about the stages of this new digital production. At this stage, the artist will either work with a specialist in a reliable studio environment or conduct extensive research and will continue to improve his/her experience by getting a professional training in this production technology. It is certain that it is not that affordable. The fact that the machinery and consumption costs of technology are at a high price is an obstacle for many artists to reach. Currently, there are the artists who prefer this technology, familiarity with the art market and the digital production belonging to the prominent artists. In Turkey, it is possible to see fine art prints of well-known painters of our country known in our country in the contemporary museums like IMOGA in contemporary museums and temporary exhibitions and in online sales (Figures 6, 7 and 8). 


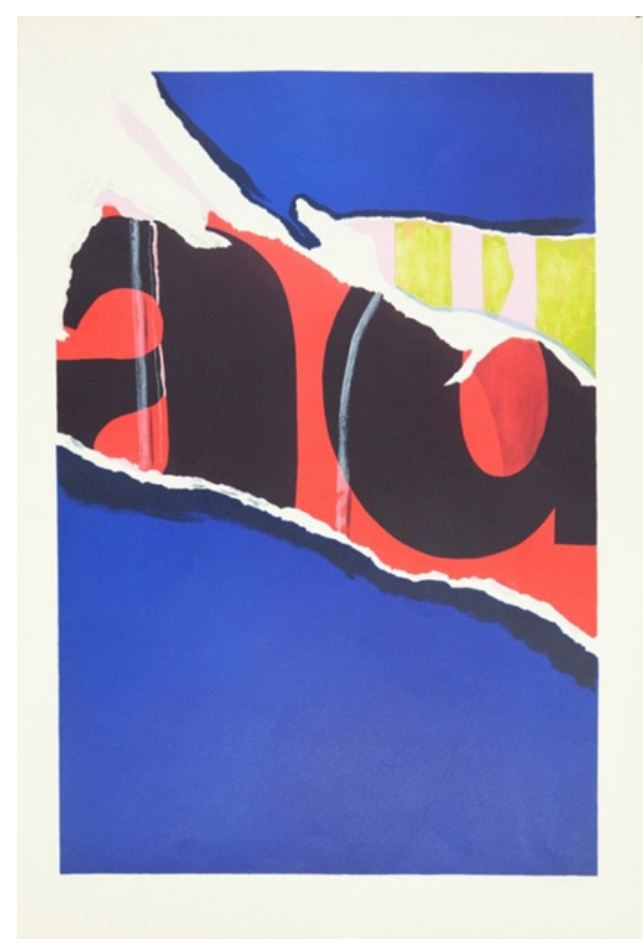

Figure 6: Burhan Dogancay, Fine Art Print, IMOGA Istanbul Museum of Graphic Art 2017, Istanbul, Turkey

Source: https://imoga.org/collections/burhandogancay/products/copy-of-burhan-dogancay-02

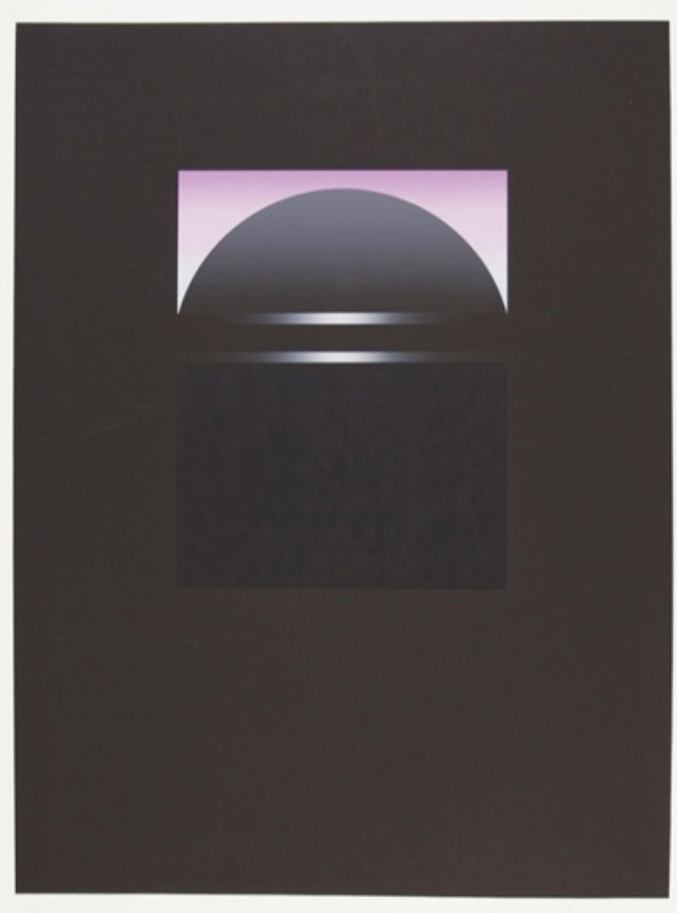

Figure 7: Adnan Coker, Fine Art Print, IMOGA Istanbul Museum of Graphic Art 2017, Istanbul, Turkey Source: From Archives Of IMOGA Istanbul Museum of Graphic Art, 2017 Istanbul

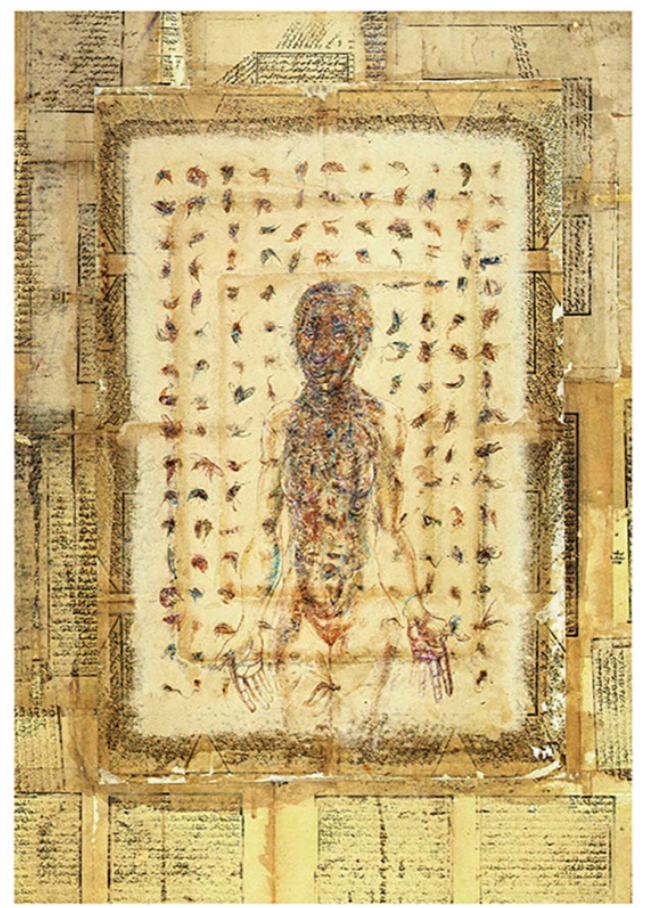

Figure 8: Ergin Inan, Fine Art Print, IMOGA Istanbul Museum of Graphic Art 2017, Istanbul, Turkey Source: From Archives Of IMOGA Istanbul Museum of Graphic Art, 2017 Istanbul 


\section{CONCLUSIONS}

Today, what is called the Millennium Age, defines a time when the art and science, and design and engineering come together and the technology itself is experienced. This unity serves humanity in many vital areas such as the business world, communication, and transportation. In this period when universities have focused on R\&D studies with multidisciplinary studies, we observe either the engineering courses in the design departments or the design courses in the engineering departments and the modern training modules following the change. In short, it is mentioned that technological developments are listed one after the other and the speed of science is difficult to follow.

In a rapidly changing social life, the contemporary artist will try to interpret this new world that she/he has lived and perceived by taking advantage of the opportunities of technology. The beginning of a new era where there is a threshold again after 100 years can be mentioned. In this technological life, it is an undeniable fact to use a technological production field that will serve to increase the accessibility of art to all segments of the society by reinterpreting. We are in the times when we witnessed the fact that contemporary artists who accept this fact are now working in a team. Edward Burtynsky, known as one of Canada's most respected photographers, is an inspiring example combining art with his internationally acclaimed scientific studies and the digital imaging and new media education center he established as a researcher as well as an artist. It is possible to illustrate many famous people who combine science with art. It is also a fact that, when there is so much flow of information, it is now a necessity to turn to the teamwork instead of being alone, to be able to discover new ways of expression as an artist. In this experimental environment, it would not be wrong to say that the works of art produced with the technology presented to the audience have enriched the artistic expression style and have been even inspiring. At this time, it is possible to see the signs that modern artists, who are open to science and innovation, will shape the art world in the future in the societies that have adapted technological life so much and, in an era, when fine art prints find a place in daily life.

From the 1990s onwards, thanks to these high-quality print courses, which have been covered by technological innovations and inkjet printers, the image quality in artistic prints has now been satisfactory for the artist. Since it is a newly discovered technological track, the problem of reaching for each artist and the high cost are concerns in terms of expenditures in Turkey. These technological tracks, which are imported and introduced to the market for the first time, are unfortunately very expensive, and therefore there are high-cost solutions for now. But in time these costs will be reduced, and in less costly times, it will be easier to supply. It is hoped that engineers and designers are trained to produce technological tracks and material that will eliminate the dependency on the import in Turkey. It is a necessity that a production technology with international standards is manufactured within country possibilities so that it is necessary to reach a stage where all kinds of machinery and consumption materials with affordable prices can be provided.

In a rapidly changing world in life, with a unique expression that captures the day, today's artists can present the works of art to the audience in dazzling exhibitions by using this technological track with the production capacity they want. Digital art prints, which cover a large space in museums, exhibitions, and architectural structures, are being discussed as a contemporary work of art as a growing value in the contemporary art market and among collectors. Today, it is not yet clear how much digital technology will provide radical changes in artistic vision. As mentioned above, it should be reiterated that these digital art prints are considered as original prints and with the signature of the artist and found in the archives of collectors in the art market. As a harbinger of a new era, fine art print expects to be discovered as an endless means of expression for contemporary artists who are beginning to find a place in the international art market.

\section{REFERENCES}

[1] Berger, M.: "The Digital Fine Art Print-Opportunities and Challenges", Proceedings of International Conference on Digital Printing Technologies adlı NIP \& Digital Fabrication Conference book, (Society for Imaging Science and Technology publishing, 2005).

[2] Beris, Y.: "Analising of the graphic design and digital printing production communication", Proceedings of Print İstanbul 2015, (Marmara University, İstanbul, 2015), pages 295-308.

[3] Ford, D.: "Andy Warhol's lost computer art found 30 years later", CNN web news, 2014, URL: http://edition.cnn.com/2014/04/24/us/andy-warhol-lost-art/index.html (last request: 2017-11-10). 
[4] Nake, F.: "Information aesthetics: an heroic experiment", Journal of Mathematics and the Arts 6(2-3), 65-75, 2012. doi: 10.1080/17513472.2012.679458.

[5] Nickelson, J.: "Fine Art İnkjet Printing - The craft and art of the fine digital print", (Rocky Nook, San Rafael, 2017).

[6] Schiuma, G.: "The Value of Arts-Based Initiatives", (Cambridge University Press, UK, 2011).

[7] Tekcan, S.: IMOGA museum visits and the notes received in the interview with the artist, November 2017.

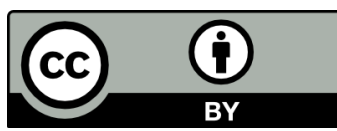

(C) 2018 Authors. Published by the University of Novi Sad, Faculty of Technical Sciences, Department of Graphic Engineering and Design. This article is an open access article distributed under the terms and conditions of the Creative Commons Attribution license 3.0 Serbia (http://creativecommons.org/licenses/by/3.0/rs/). 